\title{
IMPORTANCE OF URBAN FACTOR AND SELECTED SOCIO-ECONOMIC VARIABLES IN THE DIFFERENTIATION OF COORDINATION MOTOR ABILITIES LEVEL (CMA)
}

\author{
Coordination abilities vs. urban and socio-economic factors
}

\author{
JANUSZ JAWORSKI모 ELIGIUSZ MADEJSKI ${ }^{2}$ \\ 1 The B. Czech University School of Physical Education in Cracov, Chair of Human Movement, \\ 2 Chair of Physical Education Theory and Methodology
}

\author{
Mailing address: Janusz Jaworski, University School of Physical Education, 78 Jan Paweł II Ave., \\ 31-571 Kraków, tel.: +48 12 6831109, fax: +48 12 6831423, e-mail: janusz.jaworski@awf.krakow.pl
}

\begin{abstract}
Introduction. The aim of this study was to investigate the effects of the urban factor and socio-economic status on selected coordination motor abilities of non-practicing physical education female students. Material and methods. The research covered 83 female students aged 20.6 \pm 0.8 SD years. Data on place of residence and socio-economic status of respondents were collected through a survey. The study of coordination motor abilities was carried out by a special computer application using for this purpose a "tablet" with touch screen. Assessment of the size, scope and direction of differentiation between the groups was made on the basis of standardized inter-group differences. Results. The inter-group differences were presented in the surveyed female students' coordination motor abilities, depending on the urban factor and socio-economic status. The gradient of these changes was as follows: the city over 25 thousand population $>$ city of 25 thousand population > small town. The scale of differentiation was dependent on the type of tested abilities and the environmental factor. Conclusion. Gradient of observed changes could be caused by, e.g. more environmental stimuli stimulating the nervous system in the earlier periods of development of the female students from larger urban clusters and families with higher socio-economic status.
\end{abstract}

Key words: female students of physical education, CMA, computer tests

\section{Introduction}

The constant development of civilization confronts modern man with new challenges. In many areas of human activity it is important to have high spatial orientation, an appropriate rapid response to various signals from the outside, the balance in static and dynamic conditions and rational adjustment of motor actions to rapidly changing environmental conditions. The requirements in this regard will in the future grow even more and decide about the effectiveness of motor actions and behaviour. Because of their special role, for many years research has been conducted that allowed to isolate the specific CMA, to know their internal structure and the various methods of measurement $[1,2,3]$.

The composition of academic students covers different social groups. Academic students also derive from backgrounds of varying degrees of urbanization. This group is therefore very differentiated internally. Absence of inter-group homogeneity will cause differences in both physical development as well as motor abilities.

Somatic development of Polish students has already been studied in the interwar period, and it is observed today. Secular changes in key somatic indicators have been presented by Pilicz in his work [4]. However, since the 60s of last century the studies on level of students' motor abilities are systematically conducted. A very comprehensive review of these studies has been presented by Lisicki [5]. The material presented shows that mainly the fitness capacity was studied, but there were very few studies on the coordination abilities.

Given the foregoing, the aim of this study was to determine the impact of determinants of urbanization and socio-economic status (SES) on selected CMA of non-practicing female students of the University School of Physical Education in Kraków.

\section{Material and methods}

The research covered 83 non-practicing female students of USPE Krakow. The average age was 20.6 \pm 0.8 SD years. They were of good health and a similar physical activity and motor skills resulting from the chosen field of study. It can therefore be assumed that they represented a homogeneous group in terms of these variables. CMA was tested using a portable "tablet" computer with a touch screen. Testing of one subject (using a specially developed computer program) took about 20 minutes. The study was conducted in a separate room providing peace and quietness. The sequence of tests performed was the following: simple reaction time to visual stimuli, simple reaction time to auditory stimulus, kinesthetic differentiation, speed, accuracy and precision of movements, frequency of hand movements, a complex reaction time, eye-hand coordination and spatial orientation. When choosing the order the following principle was applied: first, simple tests were performed, and later more coordinatively complex, according to the proposed classification of 
Szopa et al. [6]. Each subject performed tests in two rounds. A short break was used before taking the frequency of movements test. Tests have been positively verified in terms of reliability and validity. Their exact description is given in the work of Sterkowicz and Jaworski [7] and Jaworski et al. [8]. Choice of the coordination tests was guided by the latest developments concerning the testing and the structure of the CMA $[1,2,3]$.

\section{Testing procedure}

1. Conducting of survey on residence of respondents and selected socio-economic variables.

2. The division of respondents into three groups depending on the size of the place of residence: I - the countryside and small towns without civic rights below 10 thousand population $(\mathrm{n}=25)$. II - small towns below 25 thousand population $(n=31)$. III - the cities over 25 thousand population $(n=27)$.

3. The designation of SES "global index" based on the sum of points of the following components: parents' education, employment of parents, number of children supported by the parents. Only 64 subjects answered these questions and they were divided into three groups in terms of SES: 5-13 points - a group of low status $(\mathrm{n}=20), 14-16$ points - a group of middle-status $(n=22), 17-21$ points - a group of high status $(n=22)$.

4. Calculating the average and SD for the CMA in distinguished groups in terms of urbanization factor and SES status. Normality of distributions was verified by the Shapiro-Wilk test. Homogeneity of variance was evaluated by Levene's test [9]. The significance of differences between CMA in groups was calculated using ANOVA variance analysis for independent samples. For different numbers post-hoc test of Tukey was used.

5. Assessing the size, scope and direction of differentiation between the two groups on the basis of standardized intergroup differences. In the case of urban factor, normalization was performed on the average and SD of subjects in group I. In the case of SES, normalization was performed on the group average of low SES and SD of all the material.

\section{Results}

Table 1 presents the average \pm SD of CMA surveyed in the three distinguished groups of urbanization. No statistically significant differences in the abilities tested, depending on the urban environment. Exceptions were the only data for the frequency of movements between group I and III. The data presented indicate that better results, although statistically insignificant, were presented by female students in group III.

The values of absolute and normalized differences for subjects in three distinguished CMA urbanization groups are given in Table 2.

The data obtained show that the place of residence was a factor differentiating the level of the respondents' coordination abilities. The scale of this variation was, however, varied depending on the features and the compared groups. Much greater differences were observed between group I and III $\left(\mathrm{z}_{2}\right)$ than between group I and II $\left(\mathrm{z}_{1}\right)$. Among all tested coordination abilities, the largest normalized differences were observed for the frequency of movements between group I and III. Definitely better results in this test showed female students in group III (approximately 1.5 SD). Effect of the degree of urbanization was also significant for kinesthetic differentiation. Normalized differences between groups for this ability were about 1.0 SD. For almost all other CMA, normalized differences $\mathrm{z}_{2}$ were slightly smaller and contained in the range from 0.23 to 0.64 SD. Of all the variables tested only for the speed, precision and accuracy of movements of female students in group I and III presented a similar level.

Table 1. Average \pm SD of the studied coordination motor abilities (CMA) of female students in the three distinguished urbanization groups

\begin{tabular}{|l|c|c|c|c|c|c|}
\hline \multicolumn{1}{|c|}{ Variable CMA / Unit } & \multicolumn{2}{|c|}{ I } & \multicolumn{2}{c|}{ II } & \multicolumn{2}{|c|}{ III } \\
\cline { 2 - 7 } & $\bar{x} \pm S D$ & $\begin{array}{c}p \\
\text { I-II }\end{array}$ & $\bar{x} \pm S D$ & $\begin{array}{c}p \\
\text { II-III }\end{array}$ & $\bar{x} \pm S D$ & $\begin{array}{c}p \\
\text { I-III }\end{array}$ \\
\hline $\begin{array}{l}\text { Kinesthetic differentiation / } \\
\text { pixels }\end{array}$ & $58.3 \pm 19.6$ & 0.226 & $44.6 \pm 21.9$ & 0.869 & $40.0 \pm 12.2$ & 0.119 \\
\hline $\begin{array}{l}\text { The frequency of move- } \\
\text { ments / number of taps }\end{array}$ & $43.5 \pm 6.4$ & 0.067 & $50.2 \pm 10.2$ & 0.561 & $53.3 \pm 3.6$ & 0.008 \\
\hline Visual reaction time / msec. & $251.5 \pm 25.0$ & 0.497 & $243.7 \pm 17.5$ & 0.573 & $236.0 \pm 15.5$ & 0.113 \\
\hline $\begin{array}{l}\text { Auditory reaction time / } \\
\text { msec. }\end{array}$ & $228.6 \pm 29.4$ & 0.689 & $221.4 \pm 25.0$ & 0.503 & $210.6 \pm 14.4$ & 0.157 \\
\hline $\begin{array}{l}\text { Reaction time with choice / } \\
\text { msec. }\end{array}$ & $385.6 \pm 65.1$ & 0.751 & $370.8 \pm 50.6$ & 0.999 & $370.7 \pm 66.6$ & 0.790 \\
\hline $\begin{array}{l}\text { Speed, accuracy and } \\
\text { precision of movements / } \\
\text { sec. }\end{array}$ & $45.8 \pm 9.1$ & 0.456 & $42.3 \pm 8.3$ & 0.651 & $45.2 \pm 7.1$ & 0.978 \\
\hline $\begin{array}{l}\text { Speed, accuracy and } \\
\text { precision of movements / } \\
\text { number of errors }\end{array}$ & $13.1 \pm 6.6$ & 0.748 & $11.4 \pm 5.5$ & 0.816 & $13.0 \pm 7.7$ & 0.998 \\
\hline $\begin{array}{l}\text { Coordination of eye move- } \\
\text { ment / sec. }\end{array}$ & $37.3 \pm 4.3$ & 0.337 & $35.5 \pm 3.3$ & 0.989 & $35.3 \pm 2.3$ & 0.339 \\
\hline Spatial orientation / sec. & $55.7 \pm 9.9$ & 0.295 & $51.8 \pm 6.8$ & 0.852 & $50.2 \pm 4.6$ & 0.148 \\
\hline $\begin{array}{l}\text { Hand-eye coordination / } \\
\text { sec. }\end{array}$ & $60.4 \pm 14.4$ & 0.494 & $54.6 \pm 15.4$ & 0.208 & $51.1 \pm 10.3$ & 0.233 \\
\hline
\end{tabular}

Explanation: I - towns below 10 thousand population, II - towns below 25 thousand population, III - towns over 25 thousand population. Digits in bold indicate significant differences between the average at $\mathrm{p} \leq 0.05$

Table 2. Volume of absolute and standardized inter-group differences after taking into account urbanization factor for the coordination of motor abilities tested

\begin{tabular}{|l|c|c|c|c|}
\hline \multicolumn{1}{|c|}{ Variable CMA / Unit } & $\mathbf{d}_{1}$ & $\mathbf{z}_{1}$ & $\mathbf{d}_{2}$ & $\mathbf{z}_{2}$ \\
\hline Kinesthetic differentiation / pixels & 13.7 & 0.69 & 18.3 & 0.93 \\
\hline The frequency of movements / number of taps & -6.7 & -1.04 & -9.8 & -1.53 \\
\hline Visual reaction time / msec. & 7.8 & 0.31 & 15.5 & 0.62 \\
\hline Auditory reaction time / msec. & 7.2 & 0.24 & 18.0 & 0.61 \\
\hline Reaction time with choice / msec. & 14.8 & 0.22 & 14.9 & 0.23 \\
\hline Speed, accuracy and precision of movements / sec. & 3.5 & 0.38 & 0.6 & 0.06 \\
\hline Speed, accuracy and precision of movements / number of errors & 1.7 & 0.25 & 0.1 & 0.01 \\
\hline Coordination of eye movement / sec. & 1.8 & 0.41 & 2.0 & 0.46 \\
\hline Spatial orientation / sec. & 3.9 & 0.39 & 5.5 & 0.55 \\
\hline Hand-eye coordination / sec. & 5.8 & 0.40 & 9.3 & 0.64 \\
\hline
\end{tabular}

Explanation: $\mathrm{d}_{1}=\bar{x}_{\text {small town }}-\bar{x}$ town below 25 thousand population;

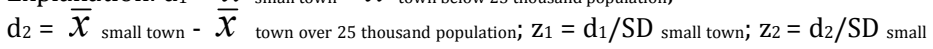
town

On the other hand, while examining the size of $\mathrm{z}_{1}$ it was found that in all cases, slightly better results were shown by female students in group II as compared with group I. The scale of these differences, however, was far smaller than between group I and III. Normalized differences between groups ranged from 0.22 to slightly more than $1.0 \mathrm{SD}$. In this case, the greatest differences were observed for frequency of movement. In summary it can be said that for most coordination capacities the urban stratification gradient was as follows: the city over 25 thousand population $>$ city of 25 thousand population $>$ small town.

Table 3 shows the average \pm SD of the tested CMA of female students in three separate groups after taking into account the socio-economic status. It has been shown that statistically significant differences occurred only in rare cases. Between groups of low and high SES, these differences occurred for auditory reaction time, reaction time with choice and precision and speed of 
movement (time of execution of the test). For differences between groups of low and middle SES, the following differences were significant: the frequency of movements and the speed and precision of movement. Only in two cases significant differences occurred between groups of high and medium SES (auditory reaction time and reaction time with choice).

The value of absolute and normalized differences for the studied CMA, depending on the socio-economic status are given in Table 4.

Table 3. Average $\pm \mathrm{SD}$ of the studied coordination motor abilities (CMA) of female students in the three distinguished groups of socio-economic status (SES)

\begin{tabular}{|l|c|c|c|c|c|c|}
\hline \multicolumn{1}{|c|}{ Variable CMA / Unit } & \multicolumn{2}{|c|}{ SES low } & \multicolumn{2}{c|}{ SES medium } & \multicolumn{2}{c|}{ SES high } \\
\cline { 2 - 7 } & $\bar{x} \pm S D$ & $\begin{array}{c}p \\
\text { I-II }\end{array}$ & $\bar{x} \pm S D$ & $\begin{array}{c}p \\
\text { II-III }\end{array}$ & $\bar{x} \pm S D$ & $\begin{array}{c}p \\
\text { I-III }\end{array}$ \\
\hline $\begin{array}{l}\text { Kinesthetic differentiation / } \\
\text { pixels }\end{array}$ & $55.5 \pm 23.4$ & 0.269 & $43.9 \pm 16.5$ & 0.982 & $42.7 \pm 28.8$ & 0.200 \\
\hline $\begin{array}{l}\text { The frequency of movements } \\
\text { / number of taps }\end{array}$ & $44.7 \pm 7.7$ & 0.024 & $52.0 \pm 9.4$ & 0.859 & $50.7 \pm 8.5$ & 0.080 \\
\hline Visual reaction time / msec. & $248.5 \pm 22.9$ & 0.976 & $247.2 \pm 18.7$ & 0.197 & $237.0 \pm 16.3$ & 0.156 \\
\hline Auditory reaction time / msec. & $228.8 \pm 30.1$ & 0.941 & $226.3 \pm 21.7$ & 0.025 & $208.7 \pm 18.3$ & 0.042 \\
\hline $\begin{array}{l}\text { Reaction time with choice / } \\
\text { msec. }\end{array}$ & $391.9 \pm 53.7$ & 0.950 & $386.7 \pm 61.1$ & 0.045 & $346.6 \pm 47.5$ & 0.028 \\
\hline $\begin{array}{l}\text { Speed, accuracy and preci- } \\
\text { sion of movements / sec. }\end{array}$ & $48.1 \pm 7.3$ & 0.042 & $41.9 \pm 8.43$ & 0.995 & $41.7 \pm 7.9$ & 0.034 \\
\hline $\begin{array}{l}\text { Speed, accuracy and preci- } \\
\text { sion of movements / number } \\
\text { of errors }\end{array}$ & $11.6 \pm 5.6$ & 0.703 & $13.3 \pm 6.7$ & 0676 & $11.6 \pm 4.5$ & 0.999 \\
\hline $\begin{array}{l}\text { Coordination of eye move- } \\
\text { ment / sec. }\end{array}$ & $37.4 \pm 2.39$ & 0.129 & $35.3 \pm 2.97$ & 0.995 & $35.4 \pm 4.5$ & 0.152 \\
\hline Spatial orientation / sec. & $55.4 \pm 6.9$ & 0.308 & $52.0 \pm 6.6$ & 0.706 & $50.2 \pm 8.4$ & 0.072 \\
\hline Hand-eye coordination / sec. & $60.0 \pm 14.7$ & 0.437 & $54.4 \pm 15.5$ & 0.848 & $52.1 \pm 12.7$ & 0.197 \\
\hline
\end{tabular}

Digits in bold indicate significant differences between the average at $\mathrm{p} \leq 0.05$.

The largest standardized difference for the CMA surveyed between groups low and high SES were obtained for auditory reaction time, reaction time with choice and speed and precision of movement (differences up to 0.8 SD). Other examined CMA were a little less differentiated by the socio-economic factors (the differences from 0.54 to $0.69 \mathrm{SD}$ ). Only in the case of the number of errors in the speed and precision of movement test there was no difference between the two groups. Differences in the size of the CMA between groups low and medium, and medium and high SES status were small. Overall, it is clear that for almost all motor skills direction of diversity was obtained in accordance with the gradient of socio-economic stratification, namely: high SES > mid SES > low SES.

Table 4. Volume of absolute and standardized inter-group differences (after taking into account of socio-economic status) for the coordination of motor abilities (CMA) tested

\begin{tabular}{|l|c|c|c|c|}
\hline \multicolumn{1}{|c|}{ Variable CMA / Unit } & $\mathbf{d}_{1}$ & $\mathbf{z}_{1}$ & $\mathbf{d}_{\mathbf{2}}$ & $\mathbf{z}_{2}$ \\
\hline Kinesthetic differentiation / pixels & 11.6 & 0.48 & 12.8 & 0.54 \\
\hline The frequency of movements / number of taps & -7.3 & -0.81 & -6.0 & -0.66 \\
\hline Visual reaction time / msec. & 1.3 & 0.06 & 11.5 & 0.58 \\
\hline Auditory reaction time / msec. & 2.5 & 0.09 & 20.1 & 0.80 \\
\hline Reaction time with choice / msec. & 5.2 & 0.09 & 45.3 & 0.79 \\
\hline Speed, accuracy and precision of movements / sec. & 6.2 & 0.74 & 6.4 & 0.77 \\
\hline Speed, accuracy and precision of movements / number of errors & -1.7 & -0.25 & 0.0 & 0.00 \\
\hline Coordination of eye movement / sec. & 2.1 & 0.60 & 2.0 & 0.58 \\
\hline Spatial orientation / sec. & 3.4 & 0.45 & 5.2 & 0.69 \\
\hline Hand-eye coordination / sec. & 5.6 & 0.38 & 7.9 & 0.54 \\
\hline
\end{tabular}

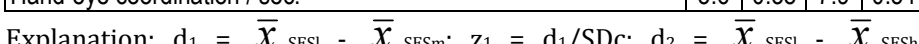
$\mathrm{z}_{2}=\mathrm{d}_{2} / \mathrm{SDc}$; SESI - status socio-economic low; SESm - status socio-economic medium; SESh - status socio-economic high; d - absolute differences; $\mathrm{z}$ - inter-group differences; SDc - standard deviation in the whole material

\section{Discussion}

Review of research on the physical fitness of students of Polish universities shows that most often the level of their fitness abilities has been evaluated [5]. The secular changes in physical and motor development of students were also regularly monitored [4]. However, there is a small number of works dealing with the influence of socio-economic and environmental impacts of CMA of academic students.

Currently, CMA are perceived as integrated psychomotor properties, determined in a dominant way by functions of the central nervous system. They are defined as relatively fixed and generalized forms of conduct of psychophysical processes of motor control [1]. A review of the literature shows that the power of the genetic and environmental factors on their level in the course of ontogenetic development is different. Among the environmental factors the following are mentioned most frequently: lifestyle including physical activity, degree of urbanization of the environment and the role of deliberately targeted practice.

Our research showed that in most cases the differences between the size of medium CMA of female students among the respondents were not statistically significant according to the declared place of residence. Similar observations on eight university students of Kraków universities were made by Mirek et al. [10]. However, in these tests, one may have noticed a tendency to obtain better academic results by the youth coming from the big city. In our study, a much clearer trend in the assessment of the size, scope and direction of changes to the CMA of the subjects, depending on the urban factor, was observed after normalization of data received to the average and SD. This trend was as follows: the city over 25 thousand population > city of 25 thousand population $>$ small village (Tab. 2). Standardized differences, however, were characteristic for their high lability depending on the analyzed feature.

The object of our search was also an attempt to assess the effects of the socio-economic factor (SES) on the tested coordination abilities. A review of the literature shows that this factor is one of the elements affecting the size of the somatic features. Results of Polish studies [11, 12, 13, 14, 15] indicate that in our country the monitoring of the impact of socio-economic modifiers on the level of somatic development is continued. Similar observations can also be found in international studies [16, 17]. Mleczko and Ozimek [18] had different observations. These researchers found that in the adolescent population of Kraków the disappearance of social gradients due to the unification of urban family life occurred. A similar biological "classlessness" was also found in some European countries [19, 20, 21]. Studies of the relationship between SES and physical fitness of children and young people in Europe are sometimes inconsistent [22, 23, 24]. However, there are works, which show that SES significantly differentiates respondents in this regard. For instance, Freitas et al. [17] studied the motor skills of children and adolescents using the "Eurofit" test. It turned out that in some age groups, boys with low SES attained the best results in tests of muscle strength and cardio-pulmonary endurance. On the other hand, girls with high SES presented the best results in power tests.

The majority of the above works focused mainly on the examination of fitness, coordination abilities were only marginally investigated. Our results indicate that in the case of female students surveyed, socio-economic factors differentiate the CMA, as well as urbanization factor does (Tab. 2). In both cases, the direction of changes in standardized inter-group differences revealed that the best results in case of CMA tested were presented by female students from the cities over 25 thousand residents and of a high socio-economic status. The scale of this variation was 
dependent on the type of tested abilities and the environmental factor.

From the viewpoint of human physiology it is reasonable to conclude that the quality of coordination processes depends mainly on the adaptability of the central nervous system [25]. The results obtained may therefore be due to, among others, more environmental stimuli that stimulate the nervous system in the earlier stages of development of children from larger population centers. In this group of factors, the special role of stimuli associated with traffic, use of the computer and the Internet should be emphasized. The availability and popularity of computers in the conditions of our country is much higher in the urban environment. Other studies indicate that a moderate number of hours devoted to computer games for children positively affect the level of many coordination abilities [26].

\section{Conclusion}

Gradient of observed changes in the size of the tested CMA could be caused by the e.g. more environmental stimuli that stimulate the nervous system in the earlier periods of development of the female students surveyed, coming from larger urban agglomerations and the families of higher socio-economic status.

\section{Literature}

1. Raczek, J., Mynarski W. \& Ljach W. (2003). Shaping and diagnosis of coordination motor abilities. Handbook for teachers, trainers and students. Katowice: AWF Katowice. [in Polish]

2. Starosta, W. (2003). Motor Coordination Abilities. Warszawa: Instytut Sporu. [in Polish]

3. Starosta, W. (2006). Global and Local Motor Coordination in Physical Education and Sport. Gorzów Wielkopolski: Zamiejscowy Wydział Kultury Fizycznej poznańskiej AWF w Gorzowie Wielkopolskim. [in Polish]

4. Pilicz, S. (1998). Secular changes in physical development and motor fitness of Polish students. Wychow. Fiz. Sport 4, 3-12. [in Polish]

5. Lisicki, T. (2002). General Physical Fitness, and Attitudes towards Health Prevention and Physical Activity of $1^{\text {st }}$ year Students. Based on the Example of Students of Trójmiasto Universities. Gdańsk: AWF Gdańsk. [in Polish]

6. Szopa, J., Mleczko E. \& Żak S. (1996). Basics of human movement. Warszawa: PWN. [in Polish]

7. Sterkowicz, S. \& Jaworski J. (2006). Assessment of reliability of own computer tests to measure the coordination of selected motor abilities (pilot study). Antropomotoryka 16(36), 81-90. [in Polish]

8. Jaworski, J., Wieczorek T. \& Lyakh W. (2007). Personal offer of a set of computers tests to measure coordination abilities. In A. Kuder et al. (Eds.), Training improvement process and sport combat (IV, pp. 29-32). Warszawa: AWF Warszawa. [in Polish]

9. Stanisz, A. (1998). Easy course of statistics. Kraków: StatSoft Polska Sp. z o. o. [in Polish]

10. Mirek, W., Mleczko E. \& Topisz-Starzewska J. (2004). Social origin and place of residence as factors differentiating the level of somatic and motor development of Krakow students. In J. Zagórski et al. (Eds.), Conditions for development of rural children and youth (pp. 789-797). Lublin: Instytut Medycyny Wsi. [in Polish]

11. Skład, M. \&Wilczewski A. (2000). The level of physical development of girls and boys. In M. Skład (Ed.), Selected indi-
Jaworski and Madejski: IMPORTANCE OF URBAN FACTOR...

cators of biological development of rural girls and boys from Podlasie (pp. 15-76). Biała Podlaska: IWFiS Biała Podlaska. [in Polish]

12. Charzewski, J. \& Piechaczek H. (2001). Inter-level differences in somatic development of children in Warsaw. Wych. Fiz. Sport 4, 421-432. [in Polish]

13. Łaska-Mierzejewska, T. \& Olszewska E. (2003). Anthropological assessment of changes in the social stratification of the rural population in Poland in the period 1967-2001. The study of girls. Warszawa: Studia i Monografie AWF Warszawa, 95. [in Polish]

14. Saczuk, J. \& Wilczewski A. (2003). Social determinants of physical development of boys and girls in rural areas. In J. Zagórski \& M. Skład (Eds.), Conditions for development of rural children and youth (32, pp. 121-132). Lublin: Monografie Instytutu Medycyny Wsi. [in Polish]

15. Zieniewicz, A. \& Popławska H. (2003). Social determinants of the level of physical development of young rural children of school age. In J. Zagórski \& M. Skład (Eds.), Conditions for development of rural children and youth (32, pp. 61-80). Lublin: Monografie Instytutu Medycyny Wsi. [in Polish]

16. Gületkin, T., Hauspuie R., Suzanne C. \& Güleç E. (2006). Growth of children living in the outskirts of Ankara: Impact of low socio-economic status. Ann. Hum. Biol. 33(1), 43-54.

17. Freitas, D., Maia J., Beunen G., Claessens A., Thomis M., Marques A. et al. (2007). Socio-economic status, growth, physical activity and fitness: The Madeira Growth Study. Ann. Hum. Biol. 34(1), 107-122.

18. Mleczko, E. \& Ozimek M. (2000). Somatic and motor development of Krakow youth between 15 and 19 years of age, taking into account environmental factors. Kraków: Studia i Monografie AWF Kraków, 14. [in Polish]

19. Brundtland, G., Liestol K. \& Walloe L. (1980). Height, weight and menarcheal age of Oslo schoolchildren during the last 60 years. Ann. Hum. Biol. 7, 307-322.

20. Lindgren, G. (1988). Auxology - education: some aspect of children's physical and mental growth in relation to socioeconomic factors in Sweden. Zagreb. Collg. Anthrop. Suppl. 228, 12.

21. Rona, R. (2000). The impact of the environment on height in Europe: Conceptual and theoretical considerations. Ann. Hum. Biol. 27, 111-126.

22. Renson, R., Beunen G., De Witte L., Ostyn M., Simons J. \& Van Gerven D. (1980). The social spectrum of physical fitness of 12 to 19-years-old boys. In M. Ostyn, G. Beunen \& J. Simons (Eds.), Kinanthropometry II. International series on sport sciences (9, pp. 104-118). Baltimore: University Park Press.

23. Taks, M., Renson R., Beunen G., Claessens A., Colla M., Lefevre J. et al. (1991). Sociogeographic variation in the physical fitness of a cross-sectional sample of Flemish girls 13 to 18 years of age. Am. J. Hum. Biol. 3, 503-513.

24. Raudsepp, L. \& Viira R. (2000). Socio-cultural correlates of physical activity in adolescents. Pediatr. Exerc. Sci. 12, 51-60.

25. Pavlović, R. (2008). Structure of students coordination. Acta Kinesiologica 1, 57-61.

26. Sterkowicz, S. \& Jaworski J. (2010). Participation in computer games vs. coordination motor abilities and body composition in boys from rural areas in Poland. CyberPsychology \& Behavior (work in printing).

Submitted: July 2, 2010

Accepted: May 5, 2011 